Article

\title{
Genome-Wide Distribution of Novel Ta-3A1 Mini-Satellite Repeats and Its Use for Chromosome Identification in Wheat and Related Species
}

\author{
Tao Lang ${ }^{1}$, Guangrong $\mathrm{Li}^{1}{ }^{1} *$, Zhihui Yu ${ }^{1}$, Jiwei $\mathrm{Ma}^{1}{ }^{1}$, Qiheng Chen ${ }^{1}$, Ennian Yang ${ }^{2}$ and \\ Zujun Yang ${ }^{1, * \mathbb{D}}$ \\ 1 Center for Informational Biology, School of Life Science and Technology, \\ University of Electronic Science and Technology of China, Chengdu 611731, China; \\ langtao123xxx@126.com (T.L); 201621090111@std.uestc.edu.cn (Z.Y.); \\ 201311090206@std.uestc.edu.cn (J.M.); 201721090218@std.uestc.edu.cn (Q.C.) \\ 2 Crop Research Institute, Sichuan Academy of Agricultural Sciences, Chengdu 610066, China; \\ yangennian@126.com \\ * $\quad$ Correspondence: ligr28@uestc.edu.cn (G.L.); yangzujun@uestc.edu.cn (Z.Y.); Tel.: +86-28-8320-6556 (Z.Y.)
}

Received: 14 January 2019; Accepted: 28 January 2019; Published: 29 January 2019

\begin{abstract}
A large proportion of the genomes of grasses is comprised of tandem repeats (TRs), which include satellite DNA. A mini-satellite DNA sequence with a length of $44 \mathrm{bp}$, named Ta-3A1, was found to be highly accumulated in wheat genome, as revealed by a comprehensive sequence analysis. The physical distribution of Ta-3A1 in chromosomes 3A, 5A, 5B, 5D, and 7A of wheat was confirmed by nondenaturing fluorescence in situ hybridization (ND-FISH) after labeling the oligonucleotide probe. The analysis of monomer variants indicated that rapid sequence amplification of Ta-3A1 occurred first on chromosomes of linkage group 5, then groups 3 and 7. Comparative ND-FISH analysis suggested that rapid changes occurred in copy number and chromosomal locations of Ta-3A1 among the different species in the tribe Triticeae, which may have been associated with chromosomal rearrangements during speciation and polyploidization. The labeling and subsequent use of Ta-3A1 by ND-FISH may assist in the precise identification and documentation of novel wheat germplasm engineered by chromosome manipulation.
\end{abstract}

Keywords: fluorescence in situ hybridization; mini-satellite; tandem repeats; wheat

\section{Introduction}

Repetitive DNA often constitutes the majority of grass genomes, but these repeated segments vary extensively from species to species in absolute amounts, sequences, and dispersion patterns [1]. Due to the rapid evolution and characteristic genomic distribution patterns, repetitive sequences have been useful for phylogenetic analysis and chromosomal identification, as well as for studying nuclear architecture [2,3]. According to the length of the repeated units and array size, tandem repeated DNA sequences can be classified into three groups, including microsatellites, mini-satellites, and satellite DNA. The mini-satellites (10-60 bp) were first described by Jeffreys et al. [4], and are usually defined as the repetition in tandem of a short (6- to 100-bp) motif spanning $0.5 \mathrm{~kb}$ to several kilobases [5,6]. Mini-satellites were first characterized in the human genome [4], where they share a common motif known as the core sequence [7], and were subsequently discovered in a variety of plant species [8-11]. A remarkable advance in the knowledge of repetitive sequences has occurred in recent years because of the introduction of next-generation sequencing technologies [12]. Bioinformatic pipelines or web servers have provided computational facilities for the identification of mini-satellites for next-generation sequence data [13-15]. The availability of genome sequences allows 
the development of site-specific mini-satellites, as has been reported for diploid and polyploid plant species [16-19].

Bread wheat, Triticum aestivum L., consists of three closely related subgenomes (A, B, D), and these genomes contain a high proportion $(>85 \%)$ of repetitive DNA $[20,21]$. Universal repetitive sequences and genome-specific repetitive sequence families have been identified in Triticeae species [22]. The mini-satellite sequences in wheat and related species have been referred to as "variable number tandem repeats" (VNTRs). The identified mini-satellite sequences in T. aestivum, T. durum Desf., T. monococcum L., Aegilops speltoides Tausch, and Ae. tauschii Coss. have shown a high degree of polymorphism among the various genomes $[23,24]$. Probes and markers for mini-satellites have been successfully used for DNA fingerprinting [11]. Extensive analysis of such mini-satellite tandem repeats is potentially useful for combining genomic and cytogenetic studies of wheat chromosomes.

The recent completion of the genomic sequencing of T. aestivum cv. Chinese Spring (International Wheat Genome Sequencing Consortium, [25]), and also the A genome donor (Triticum urartu Thumanjan ex Gandilyan) [26], the D genome progenitor (Ae. tauschii) [27], and the tetraploid wheat, Triticum dicoccoides Schrank ex Schübl. (AABB genomes [28]), provide opportunities for the localization of repetitive sequences to chromosome physical regions. Lang et al. [29] first constructed a database of repeats according to unit size, array number, and physical coverage length of TRs in the wheat genome. The comparison of tandem repeats, including satellite repeats, at genome-wide levels may potentially shed new light on our understanding of genomic amplification through evolutionary processes $[3,29,30]$.

The principal aim of the present study is to describe the physical location and sequence variations of a novel mini-satellite repeat, Ta-3A1, between wheat and its ancestors by genome-wide analysis. Fluorescence in situ hybridization by Ta-3A1 for chromosome identification and evolution of wheat and related species is also discussed.

\section{Materials and Methods}

\subsection{Plant Materials}

Common wheat cv. Chinese Spring (CS), Thinopyrum intermedium (Host) Barkworth \& D.R. Dewey, and Th. ponticum (Podp.) Z.-W.Liu \& R.-C.Wang were provided by Prof. Bikram S. Gill, Wheat Genetic and Genomic Resource Center, Kansas State University. Germplasm of Aegilops L. and Hordeum L. species were obtained from Prof. Eviatar Nevo at the Institute of Evolution, University of Haifa, Israel. The durum wheat-Dasypyrum villosum (L.) Borbás amphiploid was obtained from Prof. Huaren Jiang, Sichuan Agricultural University, China. Lines of tetraploid wheat, including T. carthlicum Nevski, T. abyssinicum L., T. durum, and T. dicoccoides, were provided by Dr. Cheng Liu, Crop Research Institute, Shandong Academy of Agricultural Sciences. Tetraploid Ae. tauschii (Zeng et al. 2012) [31], rye (Secale cereale L.), D. villosum L., hexaploid triticale cv. Currency, and the wheat-D. breviaristatum L. partial amphiploid [32] were maintained in our laboratory at the School of Life Science and Technology, University of Electronic Science and Technology of China. A list of accessions with their ploidy level and genome constitution are given in Table S1.

\subsection{Identification of Tandem Repeats (TRs)}

The wheat genome IWGSC RefSeq v1.0 assembly and genomic annotation was downloaded from (https:/ / wheat-urgi.versailles.inra.fr/). The genome-wide analysis of the tandem repeats in wheat was conducted by the Tandem Repeat Finder (TRF) algorithm [33] using alignment parameters of 2, 7 , and 7 for match, mismatch, and indels, respectively. The interpretation of TRs by number of copy, array, and cluster is illustrated in Figure S1. Tandem repeats annotated by TRF were divided into three classes according to the size of period distances $(<20,20-60$, and $>60)$. A nonredundant set of sequences was constructed using the program CD-HIT [34] at an 85\% similarity level. The distribution and chromosomally enriched locations of the clusters of TRs in wheat genome were visualized with 
the assistance of a website, B2DSC (http:/ / mcgb.uestc.edu.cn/b2dsc), according to the procedure of Lang et al. [29].

\subsection{Fluorescence In Situ Hybridization (FISH)}

Seedling roots from wheat and related species and wheat-alien derivatives were collected when they were about $2-3 \mathrm{~cm}$ long. Excised root tips were treated with nitrous oxide gas for $2 \mathrm{~h}$ under $1.0 \mathrm{MPa}$ pressure. The treated root tips were fixed in $90 \%$ acetic acid for $10 \mathrm{~min}$. After the roots were washed by distilled water, they were digested in $2 \%$ cellulase and 1\% pectolyase (Yakult Pharmaceutical, Tokyo, Japan) for $55 \mathrm{~min}$ at $37^{\circ} \mathrm{C}$. The digested root sections were washed and then mashed to form a cellular suspension in $100 \%$ acetic acid. The cell suspensions were dropped onto glass slides for chromosome preparation according to Kato et al. [35]. The synthesized oligonucleotide probes Oligo-pSc119.2 with 5' labeled by 6-carboxyfluorescein (6-FAM) and Oligo-pTa535 with 5' labeled by 6-carboxytetramethylrhodamine (Tamra) were used for identifying the wheat chromosomes according to the description of Tang et al. [36]. The oligonucleotide probes were synthesized by Shanghai Invitrogen Biotechnology Co. Ltd. (Shanghai, China). The protocol of nondenaturing FISH (ND-FISH) employing synthesized probes was described by Fu et al. [37]. After ND-FISH, the chromosome squashes for sequential FISH for Oligo-3A1 labeled by 6-FAM were washed twice, each for 5 min with $0.1 \%$ Tween 20 in $2 \times$ SSC, to remove the hybridization signals. FISH images were captured with an Olympus BX-51 microscope equipped with a DP-70 CCD camera operated by DP manager software (Olympus). Images were processed using Photoshop 3.0 (Adobe Systems Incorporated, San Jose, CA, USA).

\subsection{Sequences Variation and Phylogenetic Analysis}

The DnaSP version 6.0 [38] was used to compute DNA polymorphism and their variances. Multiple sequence alignments from different chromosomal regional accumulated Oligo-3A1 sequences were done using ClustalX [39] and were subsequently used for phylogenetic analyses. Maximum likelihood (ML) trees were constructed by MEGA7.0 [40], and the trees were displayed with FigTree v1.40 software (http://tree.bio.ed.ac.uk/software/figtree/). Clustered consensus sequences combined with the phylogenetic trees were displayed with the logos [41,42].

\section{Results}

\subsection{Ta-3A1 Was One of the Top Accumulated TRs}

A database of all the raw and filtered nonredundant TRs predicted for the IWGSC RefSeq v1.0 assembly by TRF is available at http://mcgb.uestc.edu.cn/tr [29]. The nonredundant TRs were classified into three classes based on their lengths of period distance (PD), specifically $<20 \mathrm{bp}, 20-60 \mathrm{bp}$, and $>60 \mathrm{bp}$. The distribution of different PD sizes on individual chromosomes indicated that the copy numbers of TRs of $<20$ bp were more abundant than those with $20-60 \mathrm{bp}$ and $>60 \mathrm{bp}$ (Figure 1 ). Interestingly, the TRs of 20-60 bp were highly accumulated within short regions of chromosomes $3 \mathrm{~A}$, $5 \mathrm{~A}, 7 \mathrm{~A}, 5 \mathrm{~B}$, and 5D. In order to determine the composition of the highly accumulated mini-satellite repeats in the five chromosomes, the TRs with a pattern size $\geq 20 \mathrm{bp}$, copy number $\geq 50$, and percent match $\geq 80$ were grouped. We found that a TR array with a length of $44 \mathrm{bp}$ predominated (the consensus sequence was AATAATTTTACACTAGAGTTGAACTAGCTCTA TAAGCTAGTTCA). This predominating array was named TR-3A1 and consisted of 280 nonredundant arrays covering a length of 2,630,397 bp. Across all wheat chromosomes, the estimated total predicted copy number of TR-3A1 was 59,801 , which was mainly distributed on the above five chromosomes with copy numbers of $14,987,11,083,7828,8444$, and 28,964 on chromosomes $3 \mathrm{~A}, 5 \mathrm{~A}, 7 \mathrm{~A}, 5 \mathrm{~B}$, and 5D, respectively (Table 1 ). 

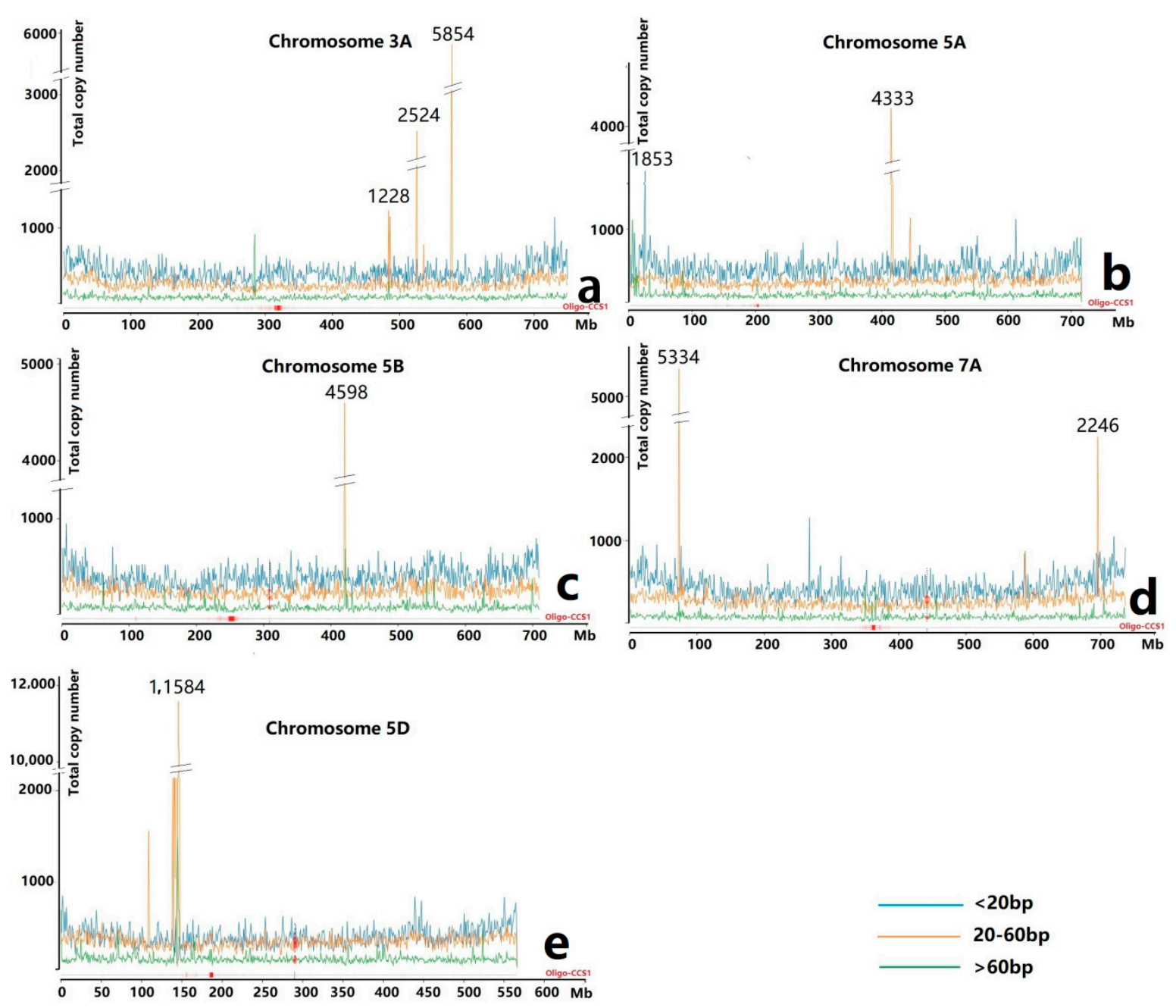

Figure 1. The copy number and distribution of tandem repeats in wheat chromosomes $3 \mathrm{~A}(\mathbf{a}), 5 \mathrm{~A}$ (b), 5B (c), 7A (d), and 5D (e). The copy number was predicted for wheat Chinese Spring genomic sequences v 1.0 at a web server at http:/ / mcgb.uestc.edu.cn/BD2SC with default parameters.

Table 1. The predicted copy numbers of Ta-3A1 on sequenced Triticum urartu, Aegilops tauschii, T. dicoccoides, and T. aestivum genomes.

\begin{tabular}{cccccc}
\hline Species & Chromosome & Copy Number & Species & Chromosome & Copy Number \\
\hline \multirow{4}{*}{ T. aestivum } & 3A & 14,987 & T. urartu & $3 \mathrm{~A}$ & 2304 \\
& 5A & 11,083 & & $5 \mathrm{~A}$ & 1199 \\
& 7A & 7828 & & $7 \mathrm{~A}$ & 835 \\
& 5B & 8444 & T. dicoccoides & $3 \mathrm{~A}$ & 2765 \\
Ae. tauschii & 5D & 28,964 & & $5 \mathrm{~A}$ & 16,482 \\
& 5D & 5404 & & $7 \mathrm{~A}$ & 6449 \\
\end{tabular}

The Ta-3A1 sequence was submitted as a query into the website B2DSC using default parameters (pident $=85$ and qcovhsp $=80$ ). An example of the entire genomic distribution, detailed chromosomal locations, as well as the sequence directional analysis of Ta-3A1 according to the website B2DSC appears in Figure 2. The predicted copy number and the estimated physical positions of Ta-3A1 (Figure 2a) resembled the 20-60 bp TR localizations in Figure 1, which suggested that Ta-3A1 was actually the principal predicted mini-satellite in wheat genome compared to the results of TR enrichment studies by Lang et al. [29]. The physical organization of Ta-3A1 on chromosome 5DS regions at 146-147 Mb 
(Figure 2b) and the head-to-head repeats of the $72.19 \mathrm{Mb}$ region in chromosome 7A (Figure 2c) were indicated in detail.

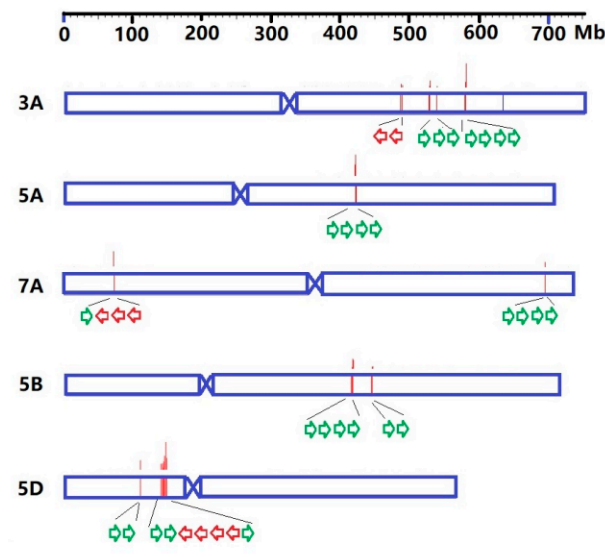

Chr, 7A: 72,192,001--72,193,000
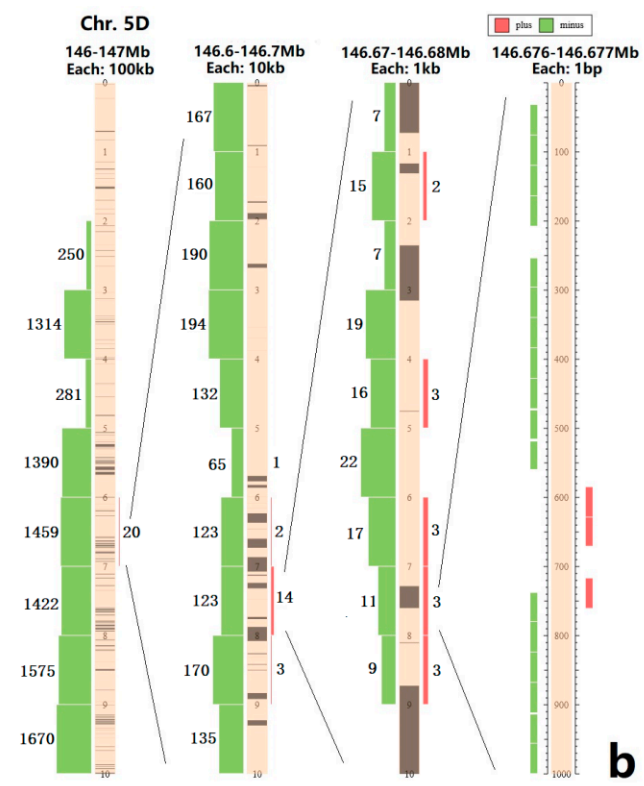

$\overrightarrow{\text { GCTCTATAGCCTAGTATAAGTAATTTTACACTAGAGTTGAACTAGCTCCATAAGCTAGTTCAAATAATTTTACACTAGAGTTGACTAGCTCTATAGCCT }}$ $\overrightarrow{\text { AGTACAAATAATTTTACACTAGAGTTGAACTAGAAATATAAGATAGTTCAAATAATTTTACACTAGAGTTGAACTAGCTCTATAAGCTAGT TGAAATAAT }}$ $\overrightarrow{\text { TTTACACTAGAGTTGCACTAGCTCTATAGCATAGTACAAATAATTTTACAGTAGAGTTGATCTAGCTCTATAATCTAGTTCAAATAATTTTACACTACAG }}$ $\overrightarrow{\text { TTGAACTAGCTCTATAAGCTAGTTCAAATAATTTTATACCAGAGTTGAACTAGCTCTATAGCCTAGTACAAATAATTTTACACTAGAATTGAACTAGCTC }}$ $\underset{\text { TATAAGCTAGTTAAAATAATTTTACACTAGAGTTGAGCTAGCTCTATAAGCAAGTTGAAATAATTTTACACTAGAGTTGAACTAGCTCTATAGCCTAGTA }}{\longrightarrow}$ CAAATAATTTTACACTAGAGTTGAACTAGCTCTATAGCCTAGTACAAATAATTTTACTCTAGTGTTAAACTAGAGTAAAATtATTTGTACTAGGCTATTG $\overline{\text { AGCTAGTTCTACTCTAGTGTAAAATTCATTGTACTAGGCTATAGAGCTAGTTCAACTCTAGTGTAAAATTATT }}$ TTAACTAGCTTATAGAGCTAGTTCAAC TCTAGTGTAAAATTTTTGAACTAGCTTATAGAGCTAGCTCAACTCTAGTGTAAAATTATT TCAACTAGCT TATAGAGATAGTTCAACTCTAGTGTAAAA TTATTTGAACTAGCTTATTGAGCTAGTTCAACTCTCGTGTAAAATTATT TGAACTAGCTTATAGAGCTAGTTCAACTCTAGTGTAAAATTATT TGTATTA

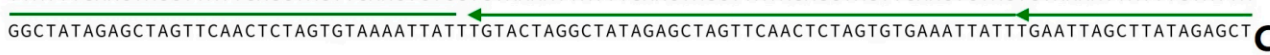

Figure 2. The predicted physical location of Ta-3A1 in wheat genome. The overview of Ta-3A1 on five chromosomes (a), copy number in a region of $5 \mathrm{D}(\mathbf{b})$, and an array of sequences on 7A (c) were indicated, respectively. The arrows represent the mini-satellite array, and green and red arrows show the minute and plus strand, respectively.

Similarly, by using the B2DSC website, the copy numbers and physical locations of Ta-3A1 were also predicted for the sequenced genomes of wheat's ancestral species, including the A genome of T. urartu [26], the D genome [27], and AABB genomes [28] (Table 1). Based on the comparison of overall genomic copy numbers of Ta-3A1 among those of the A, B, and D genomes, we found that the copy numbers on each of the corresponding chromosomes differed significantly, and the copy numbers increased from diploid to tetraploid to hexaploid wheat. The most abundant sites of Ta-3A1 were located on 5D of wheat, which was significantly higher than those on 5D of Ae. tauschii. It is likely that the copy numbers of Ta-3A1 largely increased during the polyploidization of wheat.

\subsection{Sequence Variability of Ta-3A1 on Different Chromosomal Regions}

The monomer sequences within each of the Ta-3A1 arrays spanning over 200 copies were aligned according to their diagnostic physical positions. A total of 17 clustered physical regions among the $3 \mathrm{~A}$, $5 \mathrm{~A}, 7 \mathrm{~A}, 5 \mathrm{~B}$, and $5 \mathrm{D}$ chromosomes, which represented from $17 \%$ to $43 \%$ of the nonredundant sequences, were analyzed for sequence variation rates (Table 2). Interestingly, despite their different degrees of abundance, mean $\pi$ values of Ta-3A1 monomers for each of the chromosome regions were roughly similar (from $9.3 \%$ in $5 \mathrm{~B}$ to $19.4 \%$ in $3 \mathrm{~A}$ ). The higher nucleotide diversity values $(\pi)$ on different chromosomes and different regions may suggest that the sequence variation and rearrangements of 
Ta-3A1 were due to recombination events, which may be an important force generating new monomers in chromosomes $3 \mathrm{~A}, 5 \mathrm{D}$, and $7 \mathrm{~A}$.

Table 2. Nucleotide polymorphism of the repeat features of Ta-3A1 in wheat genome.

\begin{tabular}{|c|c|c|c|c|c|c|}
\hline Chromosome & Physical Location (bp) & $N$ & $S$ & $\pi$ & $\mathrm{Hd} \pm \mathrm{SD}$ & Tajima's $D$ \\
\hline \multirow{7}{*}{$3 \mathrm{~A}$} & $484,160,160-484,477,359$ & 674 & 16 & 0.131 & $0.925 \pm 0.007$ & $-1.865^{*}$ \\
\hline & $486,643,172-486,682,396$ & 370 & 24 & 0.147 & $0.987 \pm 0.002$ & $-1.851 *$ \\
\hline & $525,926,313-525,999,776$ & 356 & 22 & 0.127 & $0.965 \pm 0.005$ & $-2.014 *$ \\
\hline & $526,002,472-526,436,842$ & 1065 & 17 & 0.150 & $0.959 \pm 0.004$ & -1.648 \\
\hline & $536,013,749-536,065,681$ & 280 & 22 & 0.144 & $0.981 \pm 0.003$ & $-1.991 *$ \\
\hline & $577,811,191-577,988,203$ & 685 & 24 & 0.155 & $0.991 \pm 0.001$ & -1.719 \\
\hline & $578,013,600-578,743,842$ & 2821 & 5 & 0.194 & $0.713 \pm 0.006$ & -0.916 \\
\hline $5 \mathrm{~A}$ & $420,664,083-420,976,973$ & 4031 & 4 & 0.159 & $0.520 \pm 0.010$ & -0.998 \\
\hline \multirow{2}{*}{$5 \mathrm{~B}$} & $412,801,830-414,820,389$ & 2806 & 9 & 0.130 & $0.765 \pm 0.007$ & -1.456 \\
\hline & $441,918,962-442,205,867$ & 616 & 22 & 0.127 & $0.973 \pm 0.004$ & $-1.920 *$ \\
\hline \multirow{5}{*}{$5 \mathrm{D}$} & $109,229,486-109,417,074$ & 908 & 19 & 0.129 & $0.948 \pm 0.005$ & $-1.843^{*}$ \\
\hline & $139,568,074-144,410,834$ & 3529 & 3 & 0.093 & $0.263 \pm 0.010$ & -1.276 \\
\hline & $146,286,068-146,411,073$ & 762 & 21 & 0.149 & $0.980 \pm 0.003$ & -1.765 \\
\hline & $146,494,968-147,180,961$ & 2924 & 9 & 0.119 & $0.693 \pm 0.010$ & -1.519 \\
\hline & $147,436,033-147,525,419$ & 570 & 22 & 0.143 & $0.983 \pm 0.003$ & $-1.883^{*}$ \\
\hline \multirow{2}{*}{$7 \mathrm{~A}$} & $72,124,011-72,576,573$ & 1466 & 14 & 0.120 & $0.866 \pm 0.008$ & -1.743 \\
\hline & $695,384,113-695,559,280$ & 621 & 22 & 0.128 & $0.970 \pm 0.004$ & $-1.942 *$ \\
\hline
\end{tabular}

Number of monomeric repeats sequenced $(N)$, number of variable sites $(S)$, nucleotide diversities $(\pi)$, and haplotype diversity (Hd). Standard deviation (SD), The estimates of the number of segregating sites and the average number of nucleotide differences correlated under the neutral model (Tajima's D). ${ }^{*}$ showed significant difference at $p<0.05$.

In order to reveal the evolutionary aspects of the overall Ta-3A1 monomer sequence variation, a phylogenetic tree of the representative Ta-3A1 satDNA in all the chromosome regions was constructed. A total of 216 representative Ta-3A1 monomer sequences predicted from the wheat genome were used for constructing the phylogenetic tree (Figure S2 and Figure 3). The results suggested that the monomers from chromosome $5 \mathrm{D}$ were separated first, the sequences of $5 \mathrm{~A}, 5 \mathrm{~B}$, and $3 \mathrm{~A}$ were categorized as the second subgroup, and the 7A sequences appeared in the third group. The sequences of chromosome 3A were mainly clustered in groups 6, 8, and 9. Combining the phylogenetic tree with the physical locations of the Ta-3A1 sequences (Figure 3), we found that the Ta-3A1 sequences from 5D distributed in most groups: However, the sequences in 5B were mainly concentrated on groups 3 and 4. This suggests that the Ta-3A1 on 5D evolved several times during sequence expansion and became more active than that of the $5 \mathrm{~B}$ chromosome. 


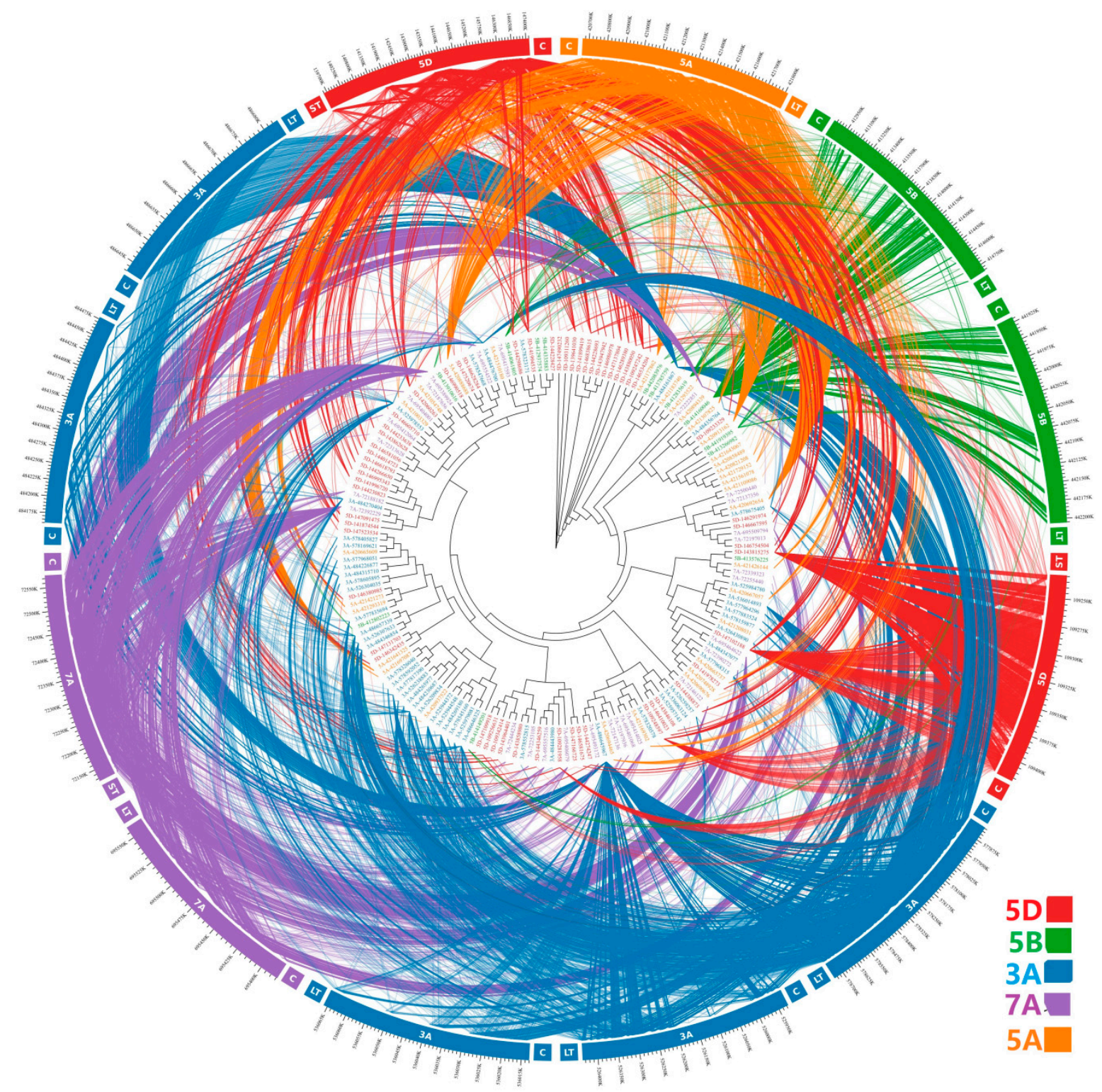

Figure 3. Phylogenetic tree of Ta-3A1 repeats and their physical location on five wheat chromosomes.

\subsection{FISH of Oligo-3A1 in Wheat}

Based on the sequences of the Ta-3A1, we produced a labeled oligo probe (Oligo-3A1) for revealing the chromosome organization of Ta-3A1 by ND-FISH analysis. Mitotic metaphase chromosomes from bread wheat, durum wheat, and some related species were prepared to study the hybridization patterns of Oligo-3A1. Sequential ND-FISH with Oligo-pTa535 and Oligo-pSc119.2 was performed for the identification of individual chromosomes of wheat [36]. As shown in Figure 4, the ND-FISH hybridization patterns of Oligo-3A1 in Chinese Spring wheat displayed strong signals on pericentromeric regions on 5DS, intercalaric regions of $5 \mathrm{AL}, 3 \mathrm{AL}$, and $5 \mathrm{BL}$, and subtelomeric regions of both arms on 7A. The chromosomal distribution of the FISH signals were consistent with the predicted copy numbers of each chromosome (Table 1). 

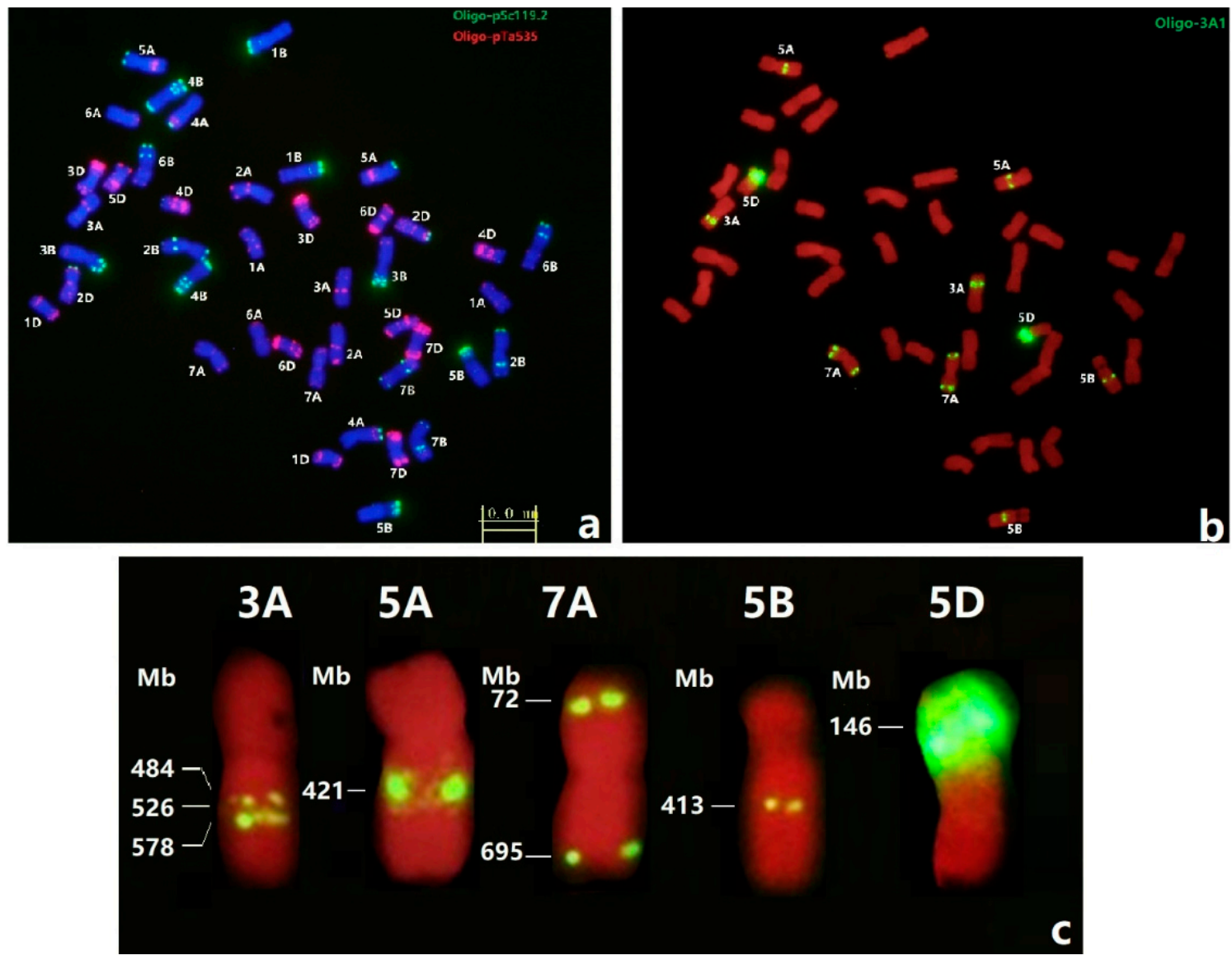

Figure 4. Nondenaturing fluorescence in situ hybridization (ND-FISH) patterns of Ta-3A1 repeats in wheat Chinese Spring: The probes Oligo-pSc119.2 (green) and pTa535 (red) (a), and sequential Oligo-3A1 (green) (b), were used for ND-FISH. The copy numbers predicted by web server page B2DSC and the copy number of Ta-3A1 at the specific region of each 1-Mb scale were illustrated in karyotypes of chromosomes (c). Bar indicated $10 \mu \mathrm{m}$.

\subsection{FISH of Oligo-3A1 in Representative Triticeae Species}

In order to shed light on the genetic divergence of Ta-3A1 on representing wheat ancestral species, the chromosome preparations from T. monococcum (A genome), Ae. longissima, Ae. searsii, Ae. speltoides (S genomes), and Ae. tauschii (D genome) accessions were carried out by ND-FISH analysis (Figure 5). The results showed that the signal strengths varied from faint to strong on $5 \mathrm{~A}^{\mathrm{m}}$ and $3 \mathrm{~A}^{\mathrm{m}}$ to $7 \mathrm{~A}^{\mathrm{m}}$ in T. monococcum (Figure 5a,d). Strong hybridization signals appeared on long arms of $5 \mathrm{~S}$ in Ae. speltoides (Figure $5 \mathrm{~b}, \mathrm{e}$ ), but conversely on the short arms of $5 \mathrm{~S}^{\mathrm{l}}$ in Ae. longissima (Figure $5 \mathrm{c}, \mathrm{f}$ ) and $5 \mathrm{~S}^{\mathrm{s}}$ in Ae. searsii (Figure 5h,k). Relatively strong signals of Oligo-3A1 were observed on 5DS of Ae. tauschii (Figure 5j,m). Therefore, the strength of signals and the localization of chromosomes varied among the wheat A, B, and $\mathrm{D}$ ancestral genomes.

A total of each of 12 T. durum, six T. dicoccoides, three T. carthlicum, and two T. abyssinicum accessions were studied by ND-FISH using Oligo-3A1 (Figure 5m-r, Table 3). We observed that the signals on chromosomes $3 \mathrm{~A}$ and $7 \mathrm{~A}$ were stable, but the strength of signals on chromosomes $5 \mathrm{~A}$ and $5 \mathrm{~B}$ varied extensively. Nine accessions showed strong signals on 5BL and weak signals on $5 \mathrm{AL}$, and the converse was noted in two accessions. The remaining accessions had equally strong hybridization signals on 5AL and 5BL. It is interesting to note that additional discrete signals were observed on chromosome 2BL of five T. durum lines, which were derived from International Maize and Wheat Improvement Center (CIMMYT) (Figure $5 \mathrm{~m}, \mathrm{p}$ ). The highly polymorphic FISH patterns of Oligo-3A1 were observed among tetraploid wheat accessions. 

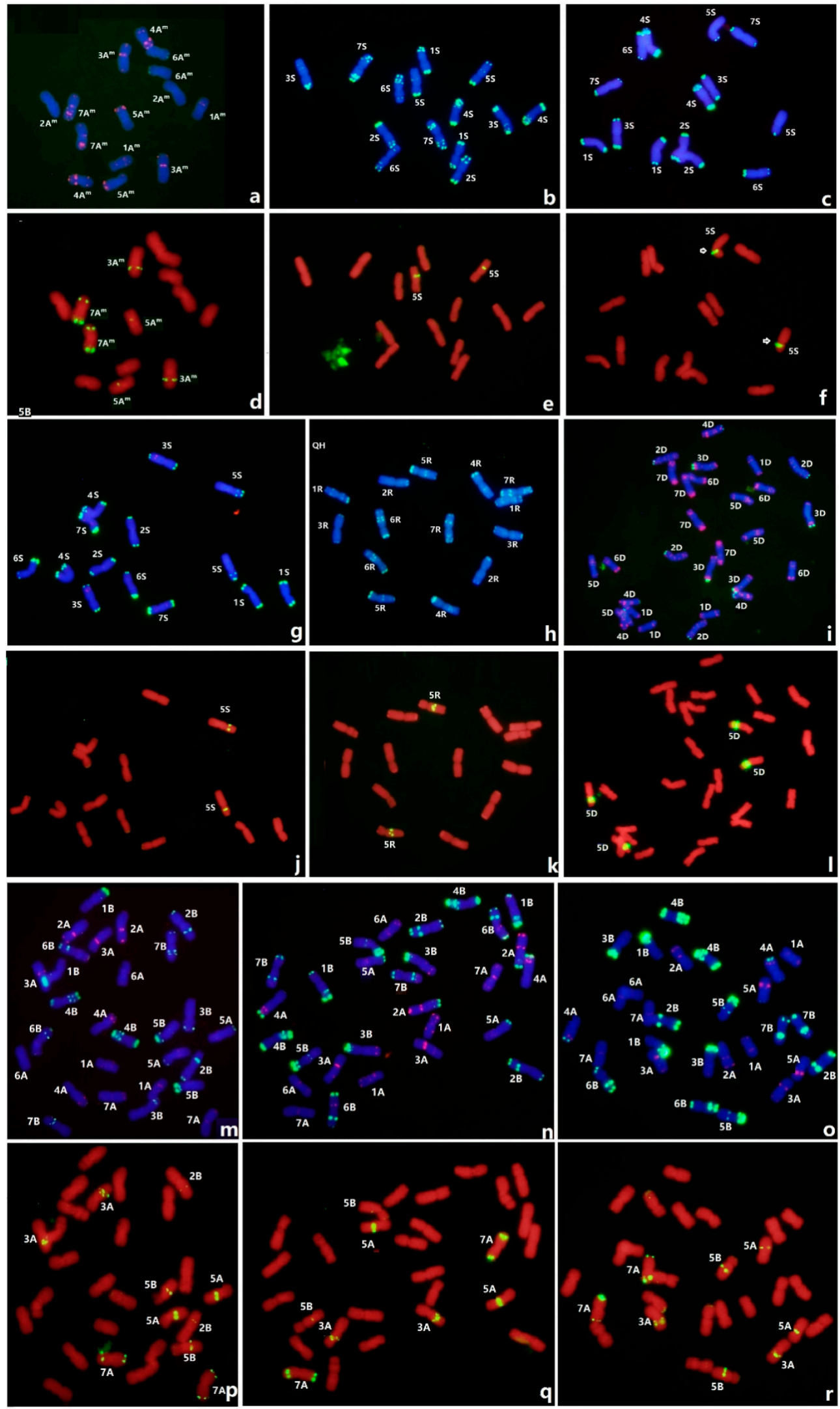

Figure 5. Hybridization of the ND-FISH probes on chromosomes of T. monococcum (a,d), Ae. speltoides $(\mathbf{b}, \mathbf{e})$, Ae. longissima $(\mathbf{c}, \mathbf{f})$, Ae. searsii $(\mathbf{g}, \mathbf{j})$, Secale cereale $(\mathbf{h}, \mathbf{k})$, tetraploid Ae. tauschii $(\mathbf{i}, \mathbf{l})$, T. durum $(\mathbf{m}, \mathbf{p})$, T. carthlicum $(\mathbf{n}, \mathbf{q})$, and T. dicoccoides (o,r). The probes Oligo-pSc119.2 (green) and pTa535 (red) $(\mathbf{a}-\mathbf{c}, \mathbf{g}-\mathbf{i}, \mathbf{o}-\mathbf{p})$, and sequential Oligo-3A1 (green) $(\mathbf{d}-\mathbf{f}, \mathbf{j}-\mathbf{l}, \mathbf{p}-\mathbf{r})$ were used, respectively. 
Table 3. The differential hybridization patterns of Ta-3A1 among tetraploid wheat.

\begin{tabular}{|c|c|c|c|c|c|}
\hline Species & Origin & Accessions & $5 B$ & $5 \mathrm{~A}$ & 2BL \\
\hline T. dicoccoides & Japan & H137 & ++ & ++ & \\
\hline T. dicoccoides & Israel & H141 & +++ & ++ & \\
\hline T. dicoccoides & Syria & $\mathrm{H} 177$ & ++ & +++ & \\
\hline T. dicoccoides & Syria & H179 & + & ++ & \\
\hline T. dicoccoides & China & $\mathrm{H} 171$ & + & ++ & \\
\hline T. dicoccoides & Israel & $\mathrm{H} 283$ & + & +++ & \\
\hline T. carthlicum & Turkey & $\mathrm{H} 149$ & + & + & \\
\hline T. carthlicum & Turkey & H94 & + & + & \\
\hline T. carthlicum & USA & AS311 & + & +++ & \\
\hline T. abyssinicum & Ethiopia & H129 & + & + & \\
\hline T. abyssinicum & Ethiopia & $\mathrm{H} 131$ & + & + & \\
\hline T. durum & CIMMYT & H281 Н322 H268 H242 & + & +++ & + \\
\hline T. durum & CIMMYT & $\mathrm{H} 246$ & ++ & +++ & + \\
\hline T. durum & CIMMYT & $\mathrm{H} 261$ & ++ & +++ & ++ \\
\hline T. durum & CIMMYT & $\mathrm{H} 242$ & + & ++ & + \\
\hline T. durum & CIMMYT & $\mathrm{H} 259$ & +++ & +++ & ++ \\
\hline T. durum & Israel & Н319 Н305 Н299 & + & +++ & \\
\hline T. durum & Israel & Langdon & + & ++ & \\
\hline
\end{tabular}

The strength of Ta-3A1 hybridization signals indicated by + (weak), ++ (medium), +++ (strong).

Additionally, ND-FISH with Oligo-3A1 was also conducted on chromosome preparations of other related wild diploid or polyploid species and wheat-alien species amphiploids. The identification of individual chromosomes from Secale [37], Dasypyrum [43], and Thinopyrum [44] was achieved by Oligo-pSc119.2 and Oligo-pTa535. Barley chromosomes were completely devoid of any hybridization signals of Oligo-3A1, as were $D$. breviaristatum chromosomes in the wheat-D. breviaristatum amphiploid. The hybridization signals of Oligo-3A1 on rye chromosome 5R (Figure 5) and in triticale (Figure $6 \mathrm{a}, \mathrm{b}$ ) were relatively strong, while the signals on $D$. villosum $5 \mathrm{~V}$ were weak in the durum wheat $-D$. villosum amphiploid (Figure 6e,f). Moreover, only two chromosomes of Th. ponticum $(2 n=10 x=70)$ appeared to carry Oligo-3A1 signals on their long arms (Figure $6 c, d)$, and only two pairs of chromosomes with Oligo-3A1 sites (one in short arms and the other in long arms) were observed for Th. intermedium $(2 n=6 x=42)$ (Figure $6 \mathrm{~g}, \mathrm{~h})$. The distribution of Ta-3A1 was polymorphic for presence/absence in different genomes or species, which suggests that the major loci were probably lost during the evolution of this polyploidy species.
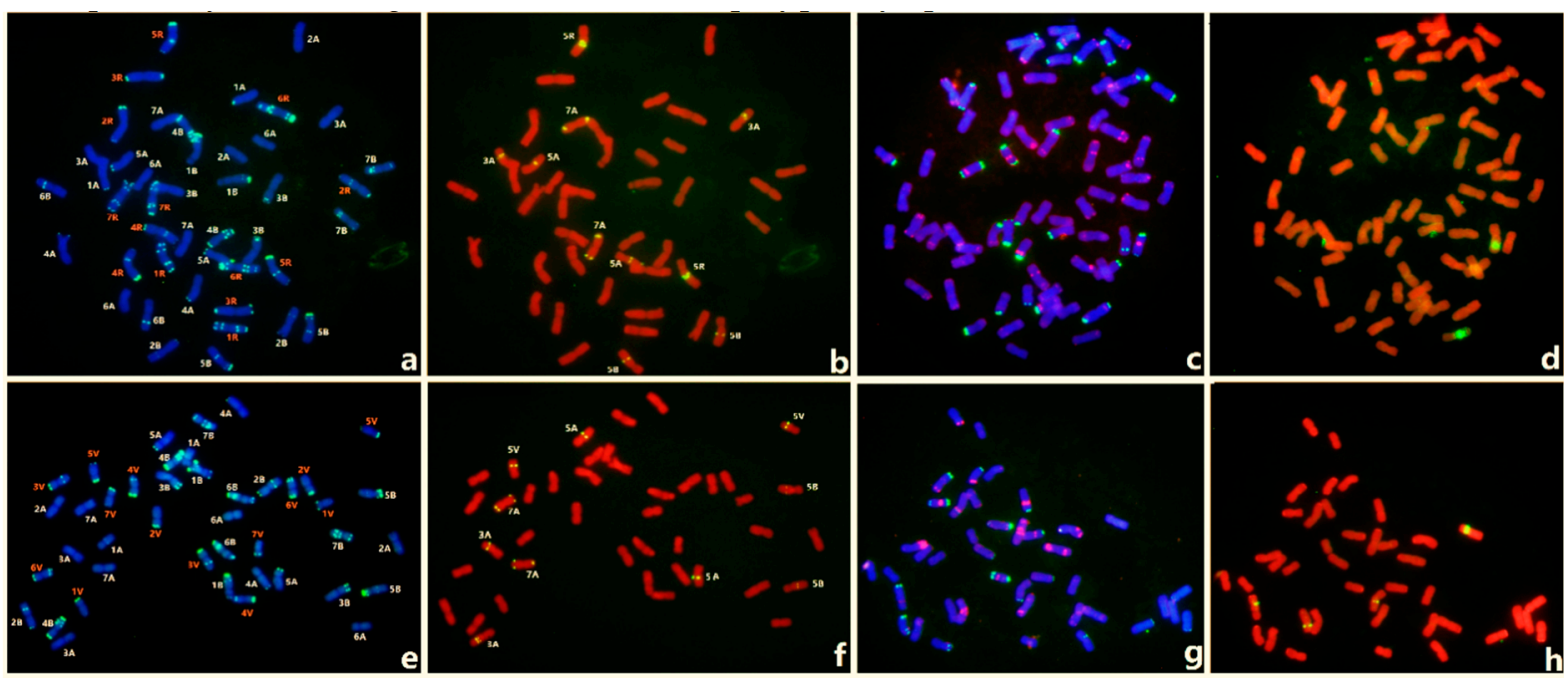

Figure 6. ND-FISH on chromosomes of hexaploid triticale $(\mathbf{a}, \mathbf{b})$, Thinopyrum ponticum (c,d), T. durum-Dasypyrum villosum amphiploid (e,f), and Th. intermedium (g,h). The probes Oligo-pSc119.2 and pTa535 (a,c,ee,g) and sequential Oligo-3A1 (b,d,f,h) were used, respectively. 


\section{Discussion}

With the recent development of next-generation sequencing technologies, an ever-increasing number of plant species have been studied and vast amounts of sequence data accumulated. Next-generation sequencing provides a convenient way to search for the presence of mini-satellite repeated sequences [14,15]. As a major class of repetitive DNA, mini-satellites consist of tandemly organized monomers. Zakrzewski et al. [16] isolated 517 novel repetitive sequences and used them for the identification of mini-satellite families in Beta vulgaris, and they revealed that mini-satellites are moderately to highly amplified by bioinformatic analysis and southern hybridization. Mogil et al. [15] identified five distinct, interleaved mini-satellite families in the pericentromeric regions of soybean (Glycine max) chromosomes, which were mediated by $>3200$ intact copies. The availability of a whole-genome assembly of wheat cv. Chinese Spring also provides opportunities to examine the distribution of retrotransposons [45] and of TRs [29] at a whole-genomic level. Our recent study predicted that TRs occupy about 3-5\% of wheat chromosomes [29]. Overall, the total array number of TR mini-satellites (20-60 bp) was 1,453,457, and the total length of such mini-satellites reached $129,873,148 \mathrm{bp}$ in the wheat genome by TRF [29]. Martienssen and Baulcombe [46] first identified mini-satellite arrays lying upstream of an alpha-amylase gene in hexaploid wheat. Somers et al. [24] amplified mini-satellite core sequences from wheat. However, these mini-satellite arrays in wheat represented moderately repeated families of less than 100 copies per array. Tang et al. [47] reported five probes with mini-satellite sequences among ND-FISH probes as predicted by TRF, and we predicted 120 to 260 copy numbers across specific chromosome regions with total lengths of under $20 \mathrm{~kb}$ by B2DSC web server. The present study found that Ta-3A1 represented the highest copy number of a mini-satellite yet reported, and it covered a total length of over $2 \mathrm{Mb}$ and was mainly located on five chromosomes of wheat (Figure 1). Two copies of Ta-3A1-like sequences were found in the intron 2 of Bradi1g11210.1 and the intron 4 of Bradi3g03878.1 in the Brachypodium genome. Ta-3A1 was absent from the sequenced barley genome [48]. With regard to the accumulation of Ta-3A1 in pericentromeric regions of chromosome 5D, the observed high number may have been related to centromeric specific retrotransposons (Figure 7). Just how the extensive duplication of the Ta-3A1 sequence on 5D occurred, which resulted in such great copy numbers, is as yet unexplained and needs to be further investigated. A problem exists with the identification of the short tandem repeats, which are often reshuffled and diversified and are somehow able to escape computational detection. The quality of assembly of the wheat genome needs to be improved through the use of single-molecule sequencing, optical mapping, and chromosome conformation capture technologies [49,50]. The updated assembly of wheat genome will offer unprecedented insights into the detection of the structural features and relevant evolutionary characteristics of TRs, including mini-satellites.
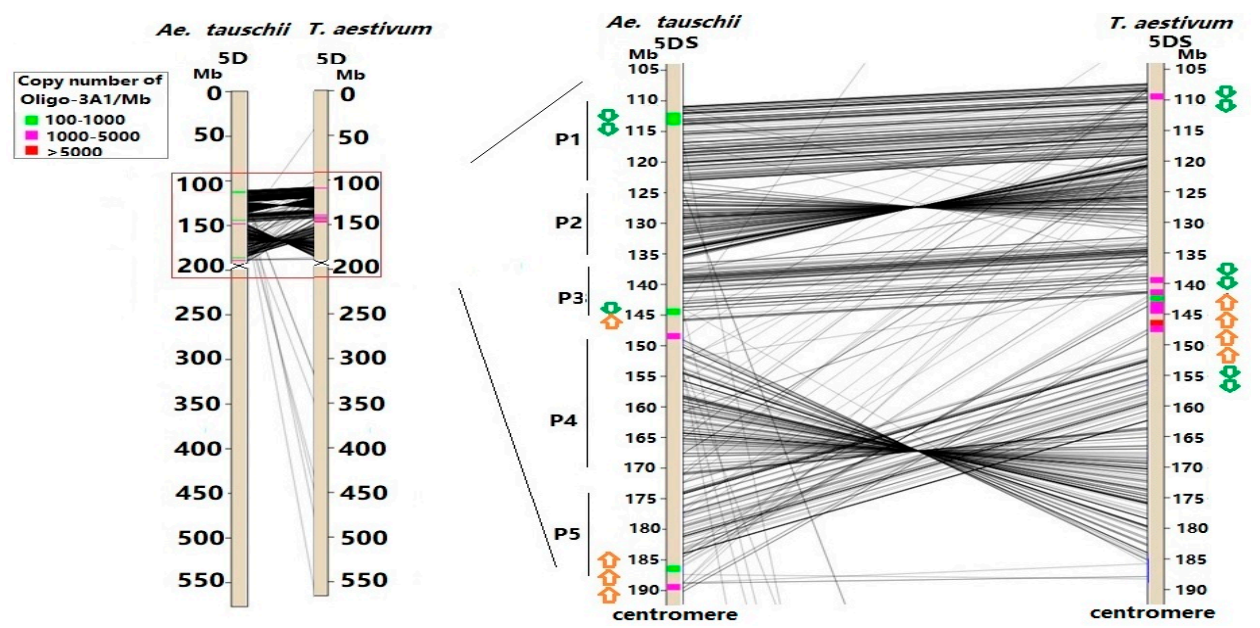

Figure 7. The genome collinearity of pericentromeric regions of chromosome 5D between Ae. tauschii and wheat Chinese Spring (CS). 
The sequence dynamics of a specific satDNA family may differ across genomic regions [51], populations [52], species, or higher taxonomic groups [53-56]. Consequently, detailed characterization of satDNA families has revealed that evolutionary patterns are more complex than previously anticipated. The study of mini-satellite sequence elements is essential to our understanding of the nature and consequences of genome size variation between different species and for studying the large-scale organization and evolution of grass genomes [5]. With regard to the ancestral species of Hordeum separated by a time period ranging from 11.6 to 15.6 Mya [48], the Ta-3A1 sequence might not have been amplified at all since no signals were detectable in wild and cultivated barley species. The $D$. breviaristatum species was also devoid of Ta-3A1 hybridization sites. It is likely that $D$. breviaristatum may be one of the ancestral Triticeae species after barley separation, which is consistent with data from our previous studies on seed gliadin evolution [57]. Bread wheat can strongly adapt to different climates, and one of the key factors of this characteristic is the allohexaploid genome structure, which originates from two distinct polyploidization events [58]. In the present study, we found that the copy number of Ta-3A1 was largely amplified from T. urartu (AA), Ae. tauschii (DD), and allotetraploid T. turgidum (AABB) to common wheat (AABBDD). Moreover, Ae. speltoides is cytogenetically distinct from the $S$ genomes of other diploid and polyploid Aegilops species based on C-banding and FISH [59,60]. We also showed that the FISH patterns of Ta-3A1 appeared on the long arm of $5 \mathrm{~S}$ in Ae. speltoides and showed close resemblance to those of the B genome in wheat. Therefore, the study of the accumulation of mini-satellite sequences can shed light on wheat genome organization and, specifically, on the role of repetitive elements by using Ta-3A1 as an example.

The satDNA family is characterized by complex features, including large variations in copy number and long-range organization of repeat units, genome location and distribution, as well as interchromosomal and intrachromosomal recombination rates [53,61-65]. Fluorescence in situ hybridization (FISH) using the probes of repetitive DNA sequences was used to determine their physical locations on individual chromosomes of common wheat and its relatives [66,67]. In this current study, we also found that Secale, Dasypyrum, and Thinopyrum species displayed varied FISH patterns of Ta-3A1 hybridization (Figure 6). It is possible to deduce trends in the complexity of Ta-3A1 organization during the evolution of the Triticeae tribe from wild species to cultivated species. The variability of Ta-3A1 representing mini-satellites has been used in numerous studies to identify plant chromosomes. The Ta-3A1 probe has been used to precisely identify the chromosomal breakage points in wheat-Th. intermedium introgression lines [68,69]. FISH specific hybridization sites by Ta-3A1 on Secale, Dasypyrum, and Aegilops chromosomes can also trace specific chromatin in wheat-alien introgression lines. The combination of both molecular cytogenetics and genomic research on TRs, including mini-satellites, will significantly benefit future wheat breeding activities, which focus on chromosome manipulation and engineering [29].

\section{Conclusions}

The mini-satellite sequences are abundantly distributed in the wheat genome, which served as powerful cytogenetic and genomic markers for germplasm enhancement and breeding practices. The present study identified a novel mini-satellite repeat Ta-3A1, and revealed its copy number and physical locations of Ta-3A1 among chromosomes of wheat and their ancestral genomes. The large sequence variation of Ta-3A1 displayed rapid evolution of mini-satellites occurred during speciation and polyploidization The Ta-3A1 based ND-FISH may be helpful for chromosome identification of wheat and related species, which can be directly used to wheat improvement by chromosome engineering.

Supplementary Materials: The following are available online at http:/ / www.mdpi.com/2073-4395/9/2/60/s1, Table S1: List of materials and their origins; Figure S1: The interpretation of TRs by numbers of individual copy, array, and cluster; Figure S2: Phylogenetic tree and sequence comparison of the Ta-3A1 repeats.

Author Contributions: Z.Y. (Zujun Yang) and G.L. designed the experiments. T.L., G.L., Z.Y. (Zhihui Yu), J.M. and Q.C. performed the experiments. Z.Y. (Zujun Yang), E.Y., and T.L. analyzed the data. Z.Y. (Zujun Yang) and G.L. wrote the paper. 
Funding: This research was funded by the National Key Research and Development Program of China (2016YFD0102000), the Applied and Basic Project (2016JY0075) from the Science and Technology Department of Sichuan, China, and the National Natural Science Foundation of China (No. 31171542).

Acknowledgments: We are thankful to Ian Dundas at the University of Adelaide, Australia, for the helpful comments on the manuscript.

Conflicts of Interest: The authors declare no conflict of interest.

\section{References}

1. Schmidt, T.; Heslop-Harrison, J.S. Genomes, genes and junk: The largescale organization of plant chromosomes. Trends Plant Sci. 1998, 3, 195-199. [CrossRef]

2. Heslop-Harrison, J.S. Comparative genome organization in plants: From sequence and markers to chromatin and chromosomes. Plant Cell 2000, 12, 617-636. [CrossRef] [PubMed]

3. Contento, A.; Heslop-Harrison, J.S.; Schwarzacher, T. Diversity of a major repetitive DNA sequence in diploid and polyploid Triticeae. Cytogenet. Genome Res. 2005, 109, 34-42. [CrossRef] [PubMed]

4. Jeffreys, A.J.; Wilson, V.; Thein, S.L. Hypervariable "minisatellite" regions in human DNA. Nature 1985, 314, 67-73. [CrossRef] [PubMed]

5. Vergnaud, G.; Denoeud, F. Minisatellites: Mutability and genome architecture. Genome Res. 2000, 10, 899-907. [CrossRef] [PubMed]

6. Mehrotra, S.; Goyal, V. Repetitive sequences in plant nuclear DNA: Types, distribution, evolution and function. Genom. Proteom. Bioinform. 2014, 12, 164-171. [CrossRef]

7. Wong, Z.; Wilson, V.; Patel, I.; Povey, S.; Jeffreys, A.J. Characterization of a panel of highly variable minisatellites cloned from human DNA. Ann. Hum. Genet. 1987, 51, 269-288. [CrossRef]

8. Rogstad, S.H.; Patton, J.C.; Schaal, B.A. M13 repeat probe detects DNA minisatellite-like sequences in gymnosperms and angiosperms. Proc. Natl. Acad. Sci. USA 1988, 85, 9176-9178. [CrossRef]

9. Broun, P.; Tanksley, S.D. Characterization of tomato DNA clones with sequence similarity to human minisatellites 33.6 and 33.15. Plant Mol. Biol. 1993, 23, 231-242. [CrossRef]

10. Tourmente, S.; Deragon, J.M.; Lafleuriel, L.; Tutois, S.; Pélissier, T.; Cuvillier, C.; Espagnol, M.C.; Picard, G. Characterization of minisatellites in Arabidopsis thaliana with sequence similarity to the human minisatellite core sequence. Nucleic Acids Res. 1994, 22, 3317-3321. [CrossRef]

11. Zhou, Z.; Bebeli, P.J.; Somers, D.J.; Gustafson, J.P. Direct amplification of minisatellite-region DNA with VNTR core sequences in the genus Oryza. Theory Appl. Genet. 1997, 95, 942-949. [CrossRef]

12. Treangen, T.J.; Salzberg, S.L. Repetitive DNA and next-generation sequencing: Computational challenges and solutions. Nat. Rev. Genet. 2011, 13, 36-46. [CrossRef] [PubMed]

13. Bally, P.; Grandaubert, J.; Rouxel, T.; Balesdent, M.H. FONZIE: An optimized pipeline for minisatellite marker discovery and primer design from large sequence data sets. BMC Res. Notes 2010, 3, 322. [CrossRef] [PubMed]

14. Abouelhoda, M.; El-Kalioby, M.; Giegerich, R. WAMI: A web server for the analysis of minisatellite maps. BMC Evol. Biol. 2010, 10, 167. [CrossRef] [PubMed]

15. Mogil, L.S.; Slowikowski, K.; Laten, H.M. Computational and experimental analyses of retrotransposon-associated minisatellite DNAs in the soybean genome. BMC Bioinform. 2012, 13, S13. [CrossRef] [PubMed]

16. Zakrzewski, F.; Wenke, T.; Holtgräwe, D.; Weisshaar, B.; Schmidt, T. Analysis of a c0t-1 library enables the targeted identification of minisatellite and satellite families in Beta vulgaris. BMC Plant Biol. 2010, 10, 8. [CrossRef] [PubMed]

17. Honma, Y.; Yoshida, Y.; Terachi, T.; Toriyama, K.; Mikami, T.; Kubo, T. Polymorphic minisatellites in the mitochondrial DNAs of Oryza and Brassica. Curr. Genet. 2011, 57, 261-270. [CrossRef] [PubMed]

18. Oliveira, G.A.F.; Dantas, J.L.L.; Oliveira, E.J. Development and validation of minisatellite markers for Carica papaya. Biol. Plant. 2015, 59, 686-694. [CrossRef]

19. Orzechowska, M.; Majka, M.; Weiss-Schneeweiss, H.; Kovařík, A.; Borowska-Zuchowska, N.; Kolano, B. Organization and evolution of two repetitive sequences, 18-24J and 12-13P, in the genome of Chenopodium (Amaranthaceae). Genome 2018, 61, 643-652. [CrossRef] [PubMed] 
20. Brenchley, R.; Spannagl, M.; Pfeifer, M.; Barker, G.L.A.; D'Amore, R.; Allen, A.M.; McKenzie, N.; Kramer, M.; Kerhornou, A.; Bolser, D.; et al. Analysis of the bread wheat genome using whole-genome shotgun sequencing. Nature 2012, 491, 705-710. [CrossRef] [PubMed]

21. Zimin, A.V.; Puiu, D.; Hall, R.; Kingan, S.; Clavijo, B.J.; Salzberg, S.L. The first near-complete assembly of the hexaploid bread wheat genome, Triticum aestivum. Gigascience 2017, 6, 1-7. [CrossRef]

22. Anamthawat-Jónsson, K.; Heslop-Harrison, J.S. Isolation and characterization of genome-specific DNA sequences in Triticeae species. Mol. Gen. Genet. 1993, 240, 151-158. [CrossRef]

23. Devos, K.M.; Bryan, G.J.; Collins, A.J.; Stephenson, P.; Gale, M.D. Application of two microsatellite sequences in wheat storage proteins as molecular markers. Theory Appl. Genet. 1995, 90, 247-252. [CrossRef] [PubMed]

24. Somers, D.J.; Zhou, Z.; Bebeli, P.J.; Gustafson, J.P. Repetitive, genome-specific probes in wheat (Triticum aestivum L. em Thell) amplified with minisatellite core sequences. Theory Appl. Genet. 1996, 93, 982-989. [CrossRef] [PubMed]

25. International Wheat Genome Sequencing Consortium (IWGSC). Shifting the limits in wheat research and breeding using a fully annotated reference genome. Science 2018, 361, eaar7191. [CrossRef] [PubMed]

26. Ling, H.Q.; Ma, B.; Shi, X.; Liu, H.; Dong, L.; Sun, H.; Cao, Y.; Gao, Q.; Zheng, S.; Li, Y.; et al. Genome sequence of the progenitor of wheat a subgenome Triticum urartu. Nature 2018, 557, 424-428. [CrossRef] [PubMed]

27. Luo, M.C.; Gu, Y.Q.; Puiu, D.; Wang, H.; Twardziok, S.O.; Deal, K.R.; Huo, N.; Zhu, T.; Wang, L.; Wang, Y.; et al. Genome sequence of the progenitor of the wheat D genome Aegilops tauschii. Nature 2017, 551, 498-502. [CrossRef] [PubMed]

28. Avni, R.; Nave, M.; Barad, O.; Baruch, K.; Twardziok, S.O.; Gundlach, H.; Hale, I.; Mascher, M.; Spannagl, M.; Wiebe, K.; et al. Wild emmer genome architecture and diversity elucidate wheat evolution and domestication. Science 2017, 357, 93-97. [CrossRef]

29. Lang, T.; Li, G.R.; Wang, H.J.; Yu, Z.H.; Chen, Q.H.; Yang, E.N.; Fu, S.L.; Tang, Z.X.; Yang, Z.J. Physical location of tandem repeats in the wheat genome and application for chromosome identification. Planta 2018. [CrossRef]

30. Evtushenko, E.V.; Levitsky, V.G.; Elisafenko, E.A.; Gunbin, K.V.; Belousov, A.I.; Šafář, J.; Doležel, J.; Vershinin, A.V. The expansion of heterochromatin blocks in rye reflects the co-amplification of tandem repeats and adjacent transposable elements. BMC Genom. 2016, 17, 337. [CrossRef]

31. Zeng, Z.X.; Hu, L.J.; Li, G.R.; Liu, C.; Yang, Z.J. Phenotypic and epigenetic changes occurred during the autopolyploidization of Aegilops tauschii. Cereal Res. Commun. 2012, 49, 476-485. [CrossRef]

32. Yang, Z.J.; Li, G.R.; Feng, J.; Jiang, H.R.; Ren, Z.L. Molecular cytogenetic characterization and disease resistance observation of wheat-Dasypyrum breviaristatum partial amphiploid and its derivatives. Hereditas 2005, 142, 80-85. [CrossRef] [PubMed]

33. Benson, G. Tandem repeats finder: A program to analyze DNA sequences. Nucleic Acids Res. 1999, 27, 573-580. [CrossRef]

34. Li, W.Z.; Godzik, A. Cd-hit: A fast program for clustering and comparing large sets of protein or nucleotide sequences. Bioinformatics 2006, 22, 1658-1659. [CrossRef] [PubMed]

35. Kato, A.; Lamb, J.C.; Birchler, J.A. Chromosome painting using repetitive DNA sequences as probes for somatic chromosome identification in maize. Proc. Natl. Acad. Sci. USA 2004, 101, 13554-13559. [CrossRef] [PubMed]

36. Tang, Z.X.; Yang, Z.J.; Fu, S.L. Oligonucleotides replacing the roles of repetitive sequences pAs1, pSc119.2, pTa-535, pTa71, CCS1, and pAWRC.1 for FISH analysis. J. Appl. Genet. 2014, 55, 313-318. [CrossRef] [PubMed]

37. Fu, S.L.; Chen, L.; Wang, Y.Y.; Li, M.; Yang, Z.J.; Qiu, L.; Yan, B.J.; Ren, Z.L.; Tang, Z.X. Oligonucleotide probes for ND-FISH analysis to identify rye and wheat chromosomes. Sci. Rep. 2015, 5, 10552. [CrossRef] [PubMed]

38. Rozas, J.; Ferrer-Mata, A.; Sánchez-DelBarrio, J.C.; Guirao-Rico, S.; Librado, P.; Ramos-Onsins, S.E.; Sánchez-Gracia, A. DnaSP 6: DNA sequence polymorphism analysis of large data sets. Mol. Biol. Evol. 2017, 34, 3299-3302. [CrossRef]

39. Larkin, M.A.; Blackshields, G.; Brown, N.P.; Chenna, R.; McGettigan, P.A.; McWilliam, H.; Valentin, F.; Wallace, I.M.; Wilm, A.; Lopez, R.; et al. Clustal W and Clustal X version 2.0. Bioinformatics 2007, 23, 2947-2948. [CrossRef] [PubMed] 
40. Kumar, S.; Stecher, G.; Tamura, K. MEGA7: Molecular evolutionary genetics analysis version 7.0 for bigger datasets. Mol. Biol. Evol. 2016, 33, 1870-1874. [CrossRef] [PubMed]

41. Schneider, T.D.; Stephens, R.M. Sequence logos: A new way to display consensus sequences. Nucleic Acids Res. 1990, 18, 6097-6100. [CrossRef] [PubMed]

42. Crooks, G.E.; Hon, G.; Chandonia, J.M.; Brenner, S.E. WebLogo: A sequence logo generator. Genome Res. 2004, 14, 1188-1190. [CrossRef] [PubMed]

43. Li, G.R.; Gao, D.; Zhang, H.J.; Li, J.B.; Wang, H.J.; La, S.X.; Ma, J.W.; Yang, Z.J. Molecular cytogenetic characterization of Dasypyrum breviaristatum chromosomes in wheat background revealing the genomic divergence between Dasypyrum species. Mol. Cytogenet. 2016, 9, 6. [CrossRef] [PubMed]

44. Li, J.B.; Lang, T.; Li, B.; Yu, Z.H.; Wang, H.J.; Li, G.R.; Yang, E.N.; Yang, Z.J. Introduction of Thinopyrum intermedium ssp. trichophorum chromosomes to wheat by trigeneric hybridization involving Triticum, Secale and Thinopyrum genera. Planta 2017, 245, 1121-1135. [CrossRef] [PubMed]

45. Wicker, T.; Gundlach, H.; Spannagl, M.; Uauy, C.; Borrill, P.; Ramírez-González, R.H.; De Oliveira, R.; International Wheat Genome Sequencing Consortium (IWGSC); Mayer, K.F.X.; Paux, E.; et al. Impact of transposable elements on genome structure and evolution in bread wheat. Genome Biol. 2018, $19,103$. [CrossRef] [PubMed]

46. Martienssen, R.A.; Baulcombe, D.C. An unusual wheat insertion sequence (WIS1) lies upstream of an $\alpha$-amylase gene in hexaploid wheat, and carries a "minisatellite" array. Mol. Gen. Genet. 1989, 217, 401-410. [CrossRef] [PubMed]

47. Tang, S.Y.; Tang, Z.X.; Qiu, L.; Yang, Z.J.; Li, G.R.; Lang, T.; Zhu, W.Q.; Zhang, J.H.; Fu, S.L. Developing new Oligo probes to distinguish specific chromosomal segments and the A, B, D genomes of wheat (Triticum aestivum L.) using ND-FISH. Front. Plant Sci. 2018, 9, 1104. [CrossRef] [PubMed]

48. Mascher, M.; Gundlach, H.; Himmelbach, A.; Beier, S.; Twardziok, S.O.; Wicker, T.; Radchuk, V.; Dockter, C.; Hedley, P.E.; Russell, J.; et al. A chromosome conformation capture ordered sequence of the barley genome. Nature 2017, 544, 427-433. [CrossRef] [PubMed]

49. Daccord, N.; Celton, J.M.; Linsmith, G.; Becker, C.; Choisne, N.; Schijlen, E.; van de Geest, H.; Bianco, L.; Micheletti, D.; Velasco, R.; et al. High-quality de novo assembly of the apple genome and methylome dynamics of early fruit development. Nat. Genet. 2017, 49, 1099-1106. [CrossRef] [PubMed]

50. Jiao, Y.; Peluso, P.; Shi, J.; Liang, T.; Stitzer, M.C.; Wang, B.; Campbell, M.S.; Stein, J.C.; Wei, X.; Chin, C.S.; et al. Improved maize reference genome with single-molecule technologies. Nature 2017, 546, 524-527. [CrossRef] [PubMed]

51. Kuhn, G.C.S.; Heslop-Harrison, J.S. Characterization and genomic organization of PERI, a repetitive DNA in the Drosophila buzzatii cluster related to DINE-1 transposable elements and highly abundant in the sex chromosomes. Cytogenet. Genome Res. 2011, 132, 79-88. [CrossRef] [PubMed]

52. Wei, K.H.C.; Grenier, J.K.; Barbash, D.A.; Clark, A.G. Correlated variation and population differentiation in satellite DNA abundance among lines of Drosophila melanogaster. Proc. Natl. Acad. Sci. USA 2014, 111, 18793-18798. [CrossRef]

53. Macas, J.; Navrátilová, A.; Koblížková, A. Sequence homogenization and chromosomal localization of VicTR-B satellites differ between closely related Vicia species. Chromosoma 2006, 115, 437-447. [CrossRef] [PubMed]

54. Kuhn, G.C.S.; Sene, F.M.; Moreira-Filho, O.; Schwarzacher, T.; Heslop-Harrison, J.S. Sequence analysis, chromosomal distribution and long-range organization show that rapid turnover of new and old $\mathrm{pBuM}$ satellite DNA repeats leads to different patterns of variation in seven species of the Drosophila buzzatii cluster. Chromosome Res. 2008, 16, 307-324. [CrossRef] [PubMed]

55. Martinsen, L.; Venanzetti, F.; Johnsen, A.; Sbordoni, V.; Bachmann, L. Molecular evolution of the pDo500 satellite DNA family in Dolichopoda cave crickets (Rhaphidophoridae). BMC Evol. Biol. 2009, 9, 301. [CrossRef] [PubMed]

56. Plohl, M.; Petrović, V.; Luchetti, A.; Ricci, A.; Šatović, E.; Passamonti, M.; Mantovani, B. Long-term conservation vs high sequence divergence: The case of an extraordinarily old satellite DNA in bivalve mollusks. Heredity 2010, 104, 543-551. [CrossRef] [PubMed]

57. Li, G.R.; Lang, T.; Yang, E.N.; Liu, C.; Yang, Z.J. Characterization and phylogenetic analysis of $\alpha$-gliadin gene sequences reveals significant genomic divergence in Triticeae species. J. Genet. 2014, 93, 725-731. [CrossRef] [PubMed] 
58. International Wheat Genome Sequencing Consortium (IWGSC). A chromosome-based draft sequence of the hexaploid bread wheat (Triticum aestivum) genome. Science 2014, 345, 1251788. [CrossRef]

59. Badaeva, E.D.; Friebe, B.; Gill, B.S. Genome differentiation in Aegilops. 1. Distribution of highly repetitive DNA sequences on chromosomes of diploid species. Genome 1996, 39, 293-306. [CrossRef]

60. Ruban, A.S.; Badaeva, E.D. Evolution of the S-Genomes in Triticum-Aegilops alliance: Evidences from chromosome analysis. Front. Plant Sci. 2018, 9, 1756. [CrossRef]

61. Luchetti, A.; Cesari, M.; Carrara, G.; Cavicchi, S.; Passamonti, M.; Scali, V.; Mantovani, B. Unisexuality and molecular drive: Bag320 sequence diversity in Bacillus taxa (Insecta Phasmatodea). J. Mol. Evol. 2003, 56, 587-596. [CrossRef] [PubMed]

62. Robles, F.; de la Herrán, R.; Ludwig, A.; Ruiz Rejón, C.; Ruiz Rejón, M.; Garrido-Ramos, M.A. Evolution of ancient satellite DNAs in sturgeon genomes. Gene 2004, 338, 133-142. [CrossRef] [PubMed]

63. Meštrović, N.; Castagnone-Sereno, P.; Plohl, M. Interplay of selective pressure and stochastic events directs evolution of the MEL172 satellite DNA library in root-knot nematodes. Mol. Biol. Evol. 2006, 23, 2316-2325. [CrossRef] [PubMed]

64. Navajas-Pérez, R.; Quesada del Bosque, M.E.; Garrido-Ramos, M.A. Effect of location, organization, and repeat-copy number in satellite-DNA evolution. Mol. Genet. Genom. 2009, 282, 2316-2325. [CrossRef] [PubMed]

65. Giovannotti, M.; Cerioni, P.N.; Splendiani, A.; Ruggeri, P.; Olmo, E.; Barucchi, V.C. Slow evolving satellite DNAs: The case of a centromeric satellite in Chalcides ocellatus (Forskål, 1775) (Reptilia, Scincidae). Amphibia-Reptilia 2013, 34, 401-411. [CrossRef]

66. Komuro, S.; Endo, R.; Shikata, K.; Kato, A. Genomic and chromosomal distribution patterns of various repeated DNA sequences in wheat revealed by a fluorescence in situ hybridization procedure. Genome 2013, 56, 131-137. [CrossRef]

67. Danilova, T.V.; Akhunova, A.R.; Akhunov, E.D.; Friebe, B.; Gill, B.S. Major structural genomic alterations can be associated with hybrid speciation in Aegilops markgrafii (Triticeae). Plant J. 2017, 92, 317-330. [CrossRef]

68. Lang, T.; La, S.X.; Li, B.; Yu, Z.H.; Chen, Q.H.; Li, J.B.; Yang, E.N.; Li, G.R.; Yang, Z.J. Precise identification of wheat-Thinopyrum intermedium translocation chromosomes carrying resistance to wheat stripe rust in line Z4 and its derived progenies. Genome 2018, 61, 177-185. [CrossRef]

69. Yu, Z.H.; Wang, H.J.; Xu, Y.F.; Li, Y.S.; Lang, T.; Yang, Z.J.; Li, G.R. Characterization of chromosomal rearrangement in new wheat-Thinopyrum intermedium addition lines carrying Thinopyrum-Specific grain hardness genes. Agronomy 2019, 9, 18. [CrossRef] 